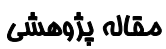

\section{مقايسه مولفه هاى شخصيتى و راهبر دهاى مقابله ایى در مردان مبتلا به اعتياد به مواد مخدر و افراد فير معتاد}

\author{
دينا كاملى'، سيد كاوه حجت '**، محمود جاجرمى '، عبدالعلى عابدى '، طيبه كاملى ه
}

'كارشناس ارشد روانشناسى عمومى، دانشخاه آزاد اسلامى واحد تربت جام، تربت جام، ايران

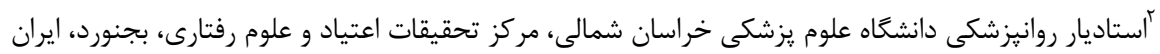

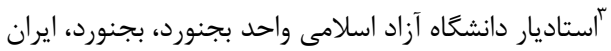

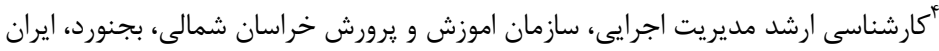

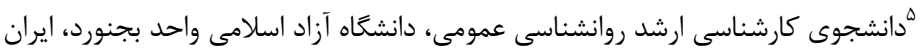

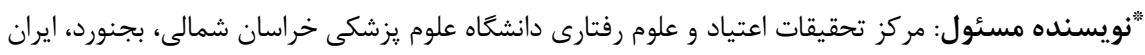
يست الكترونيك: S.kavehhojjat1@gmail.com

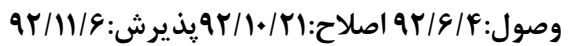

جكيده

زمينه و هدف: در درمان سوء مصرف مواد، توجه به مشكلات شخصيتى و شيوه هاى مقابله اى بيماران حائز اهميت است. اين بثرهش بـا

هدف بررسى مقايسه اى بين مولفه هاى شخصيتى و راهبردهاى مقابله الى در معتادين به مواد مخدر و افراد غير معتاد صورت كرفت مان.

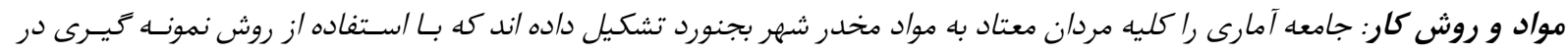

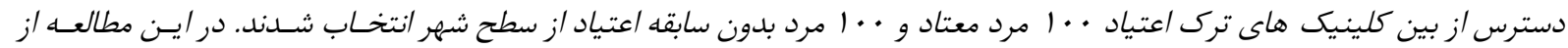

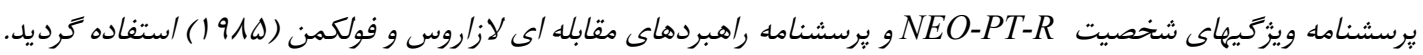

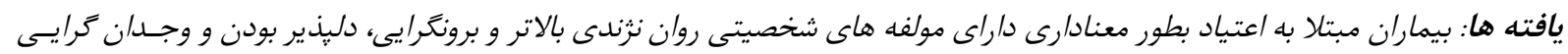

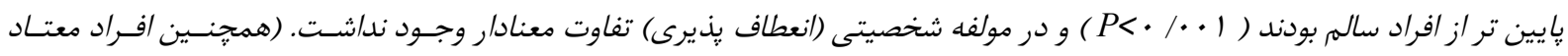

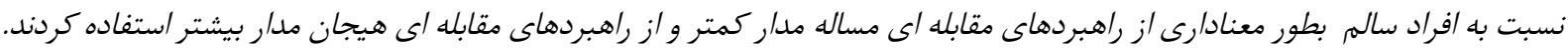
$(P=\cdot / \Gamma \varphi Q)$ نتيجه تحيرى: هرجند بيماران مبتلا به اعتياد داراى خصوصيات شخصيتى متفاوت هستند و / ماين خصوصيات تـاثير بـارزى بـر راهكارهـاى

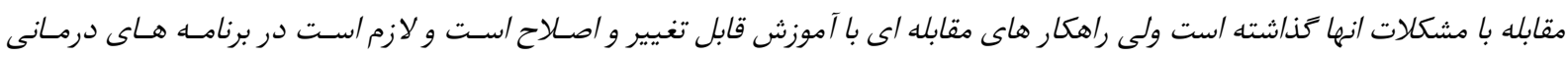

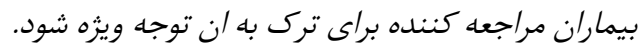
وازه هاى كليدى: شخصيت، راهبردهاى مقابله، اعتياد، مردان

برشمرد و ايران را جزء كشورهاى يرخطر دسته بندى

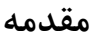

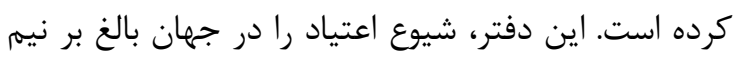
اعتياد را مى توان به اجبار در مصرف دارو يا از دست دادن درصد و اين رقمم را در كشور ايران يك تا دو درصد و مرى كنترل و مصرف بيش از حد مواد مخدر، به رغم آنكه

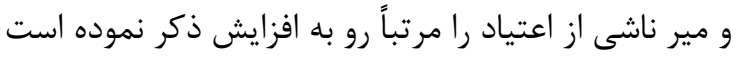

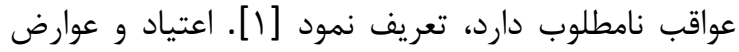
[r] خصوصيات روانى -شخصيتى معتادان به مواد مخدر ناشى از سوء مصرف مواد يكى از معضلات بزرگ در جهان

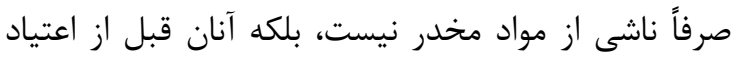

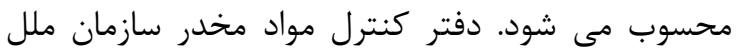
داراى نارسائى روانى و شخصيتى عديده اى بوده اند كه اعتياد را يكى از بحران هاى جهار گانه جهان (UNDOC) 
لازاروس 'و فولكمن ؛ راهبرد هاى مقابله اى انسان ها در برابر استرس هى زندگى را بصورت جامعى مورد مطالعه

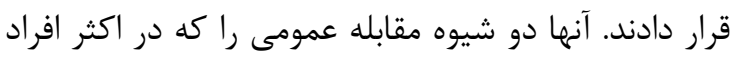

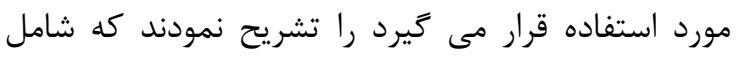

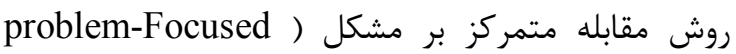
Emotional-) و مقابله متمركز بر هيجان (coping

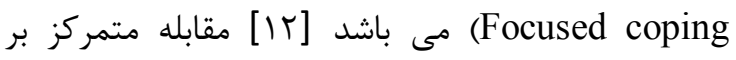
مشكل، مهارتى است كه بر يرداختن به خود مسئله يا ماند موقعيت تمركز دارد و مقابله هيجان مدار معطوف به مهار ناراحتى هيجانى بوده و به عواطفى كه بارد با آن موقعيت

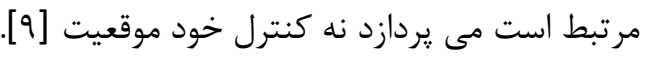

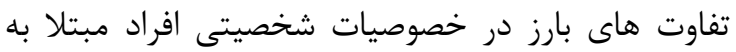

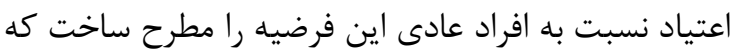

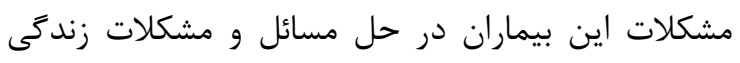
خود مرتبط با ويزگى هاى شخصيتى آنها است و بسيارى از اين ويزگى ها جنبه زنتيكى وارثى داشته و اغلب قابل

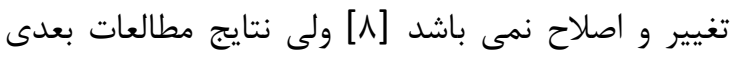

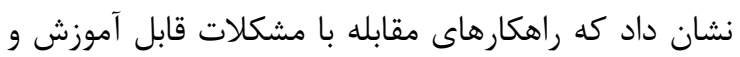

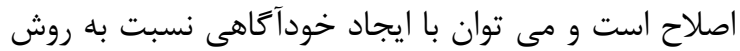
برخورد افراد با استرس هاى زندكى و درى بـ راهكارهاى

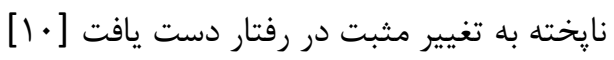

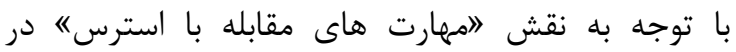

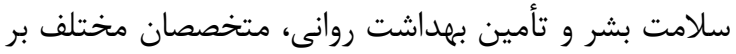

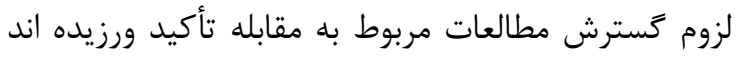
بر اين اساس، هدف يزوهش حاضر نيز بررسى مولفه هاى شخصيت و ميزان استفاده از راهبردهاى مقابله در معتادين به مواد مخدر و مقايسه آن با كروه افراد غير معتاد است.

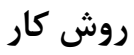
مطالعه حاضر از نوع على ـ مقايسه اى است. جامعه ى رئ آمارى در اين يزوهش شامل كليه مردان معتاد مراجعه

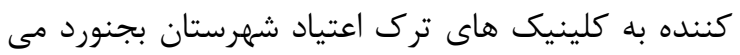

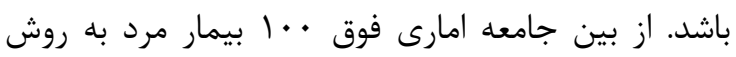

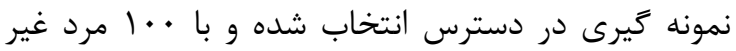

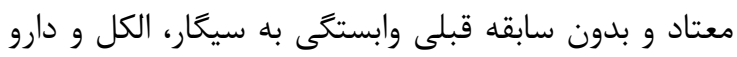

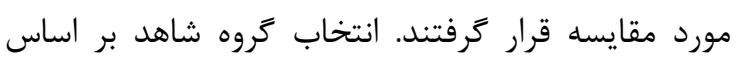

بعد از اعتياد به صورت مخرب ترى ظاهر و تشديد شده،

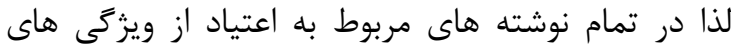

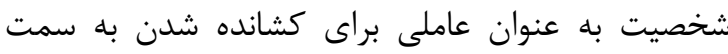
اعتياد ذكرى به ميان آمده است. به عبارت براي ديكر عده كثيرى از معتادان افرادى هستند كه داراى نارسائى امدي

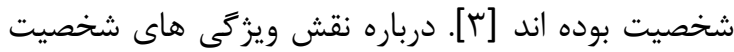
بر رفتار اعتيادى، بررسى هاى زيادى انجام شده است. اين

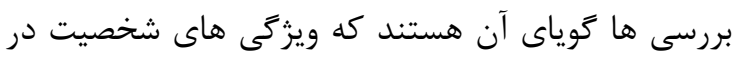
شروع، كسترش و تداوم وابستخى به مواد نقش دارند [؟].

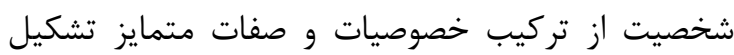

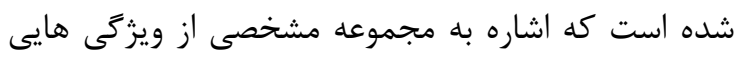

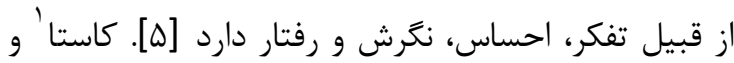

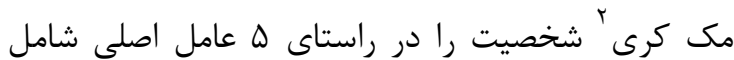
روان نزندى، برونكرايى، گَشودىى در برابر تجربه، توافق

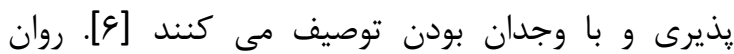
نزندى به تمايل براى تجربه اضطراب، تنش، خود خورى، بون توريف

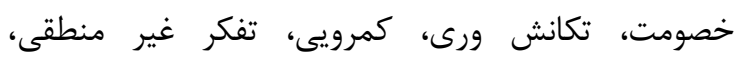

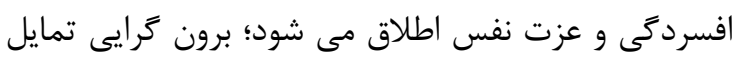

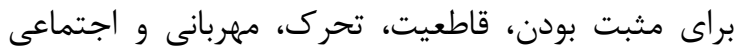

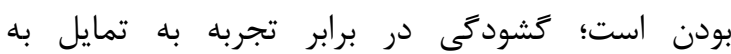

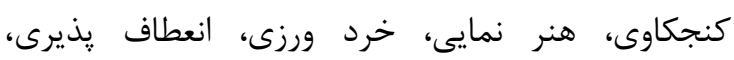
روشنفكرى، و نوآورى كفته مى شود. توافق يذيرى، تمايل

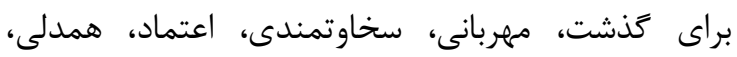
فرمانبردارى، فداكارى و وفادارى در نظر كرفته مى شود و و در نهايت با وجدان بودن به عنوان تمايل به سازمانداندي، كارآمدى، قابليت اعتماد، خويشتن دارى، منطق برايت برايى و

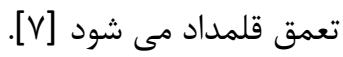
خصوصيات شخصيتى در هر انسان كاملا جنبه منحصر بـ لهاد

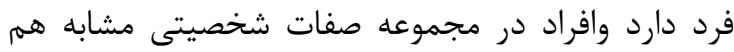
نيستند. ويزگى هاى شخصيتى مى تواند بر واكنش هاى

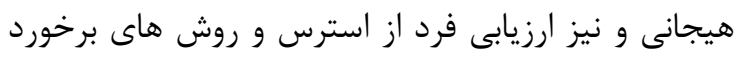

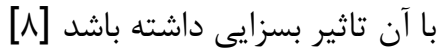

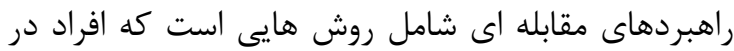

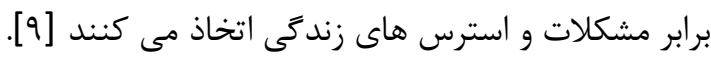


اجتناب از اين منبع در جهت كاهش اهميت آن به كار مى هـ برند. جستجوى حمايت هاى اجتماعى تلاش هاى فرد براى كسب حمايت اطلاعاتى و حمايت هاى ملموس حمايت هاى عاطفى را بازَّ مى نمايد. مسئوليت يذيرى

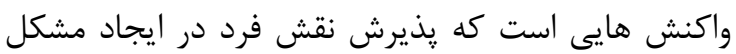
را از طريق تلاش هاى مداوم او در اصلاح موقعيت موجود

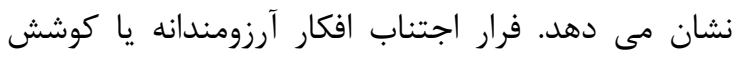
هاى رفتارى در جهت فرار يا اجتناب از موقعيت مشكل زا زائ را توصيف مى كند و شامل كريز از موقعيت است. مشكل

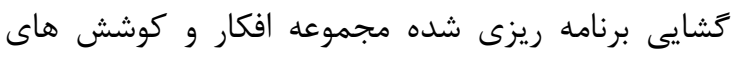
سنجيده و متمركز برخورد با مشكل توام بام با بكاركيرى رويكردهاى تحليل كرايانه براى مشكل گشايى مى باشد. ارزيابى مجدد مثبت مجموعه تلاش هايى است كه در درائر جهت ايجاد مفاهيم مثبت با توجه به درجه تكامل فردى

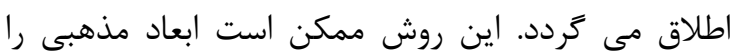

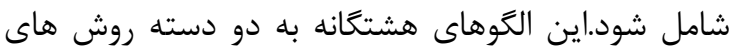

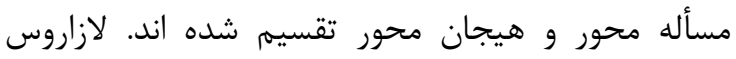

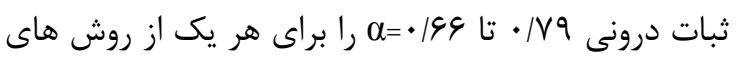
مقابله اى تزارش كرده است. آلفاى كرنباخ براى راهبرد

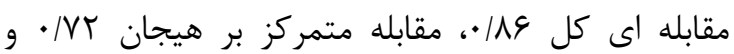

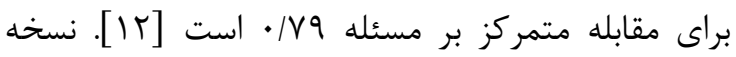

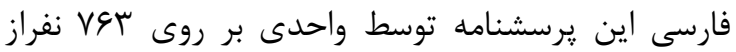
دانش آموزان دوم و سوم دبيرستان مورد ارزيابى قرار

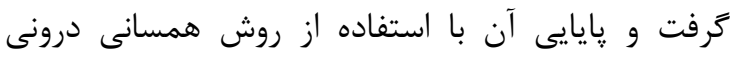

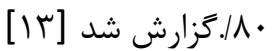
روش تحليل آمارى: در بخش تجزيه و تحليل آمارى براى آلراى

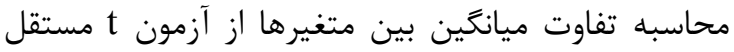

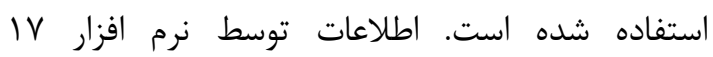
مورد تحليل قرار كرفت. SPSS

يافته ها

يافته هاى يروهش نشان داد إد ميانخين سنى افراد نمونه

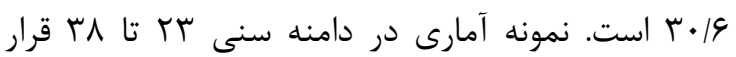

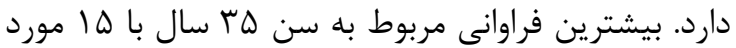
است. - است

از كل نمونه مورد تحقيق، هأدرصد زير دييلم، الب درصد

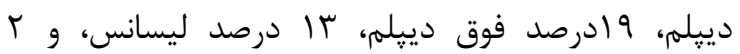
درصد از افراد فوق ليسانس بودند.
همسان سازى يك به يك و بر اساس ينج متغيير سن،

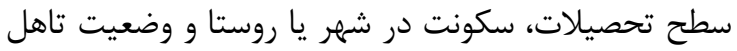
و شاغل يا بيكار با تروه مبتلا به اعتياد همسان شدند. سيس دو گروه توسط دو يرسشنامه مورد مقايسه قرار كرفتند. ابزار هاى مورد استفاده در اين يزوهش تروس شامل

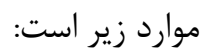
يرسشنامه ويثَّى هاى شخصيت نئو: آزمون شخصيت

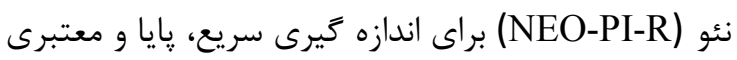

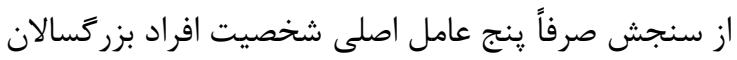

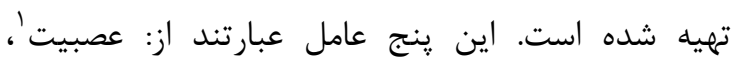

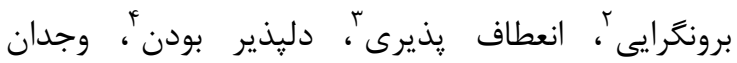

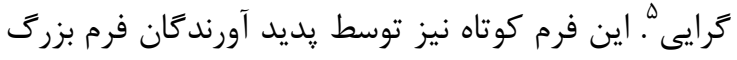

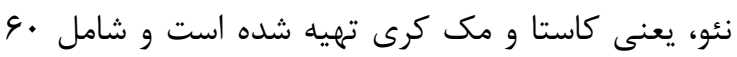

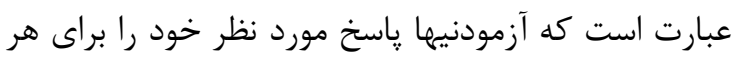

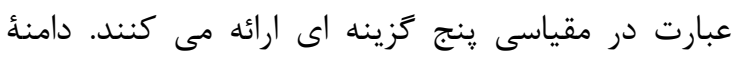

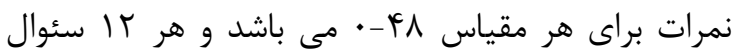

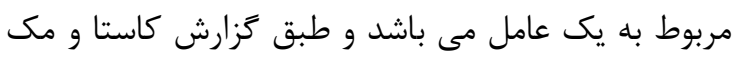

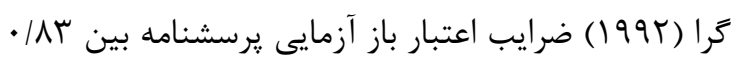
تا كوV/• است [ع] ضرايب همسانى درونى نيز در يزوهش تروسى فرشى براى اسى

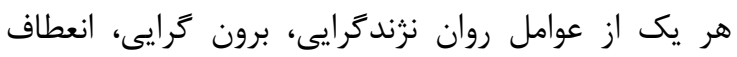

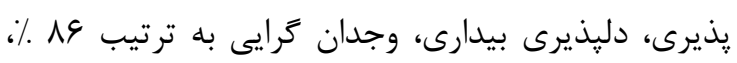

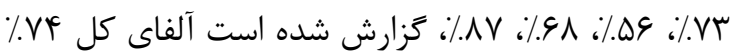

بدست آمده است [11] يرسشنامه راههاى مقابله اى لازاروس و فولكمن (1919) (1): اين يرسشنامه كه توسط لازاروس و فولكمن در سال

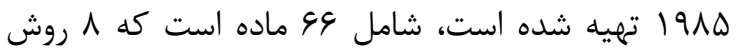
مقابله ایى را بر مى كيرد. مقابله رويارويى، مجموعه رئه رفتار

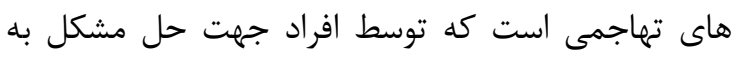
كار مى رود و متضمن درجاتى از ابزار خصومت و بكار تهار

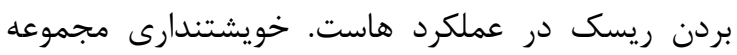
عكس العمل هايى است كه واكنش هاى احساساتى افراد

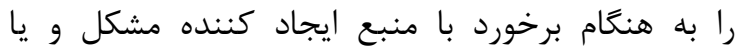

1-Neuroticism

2- Extravertion

3-Upended

4-Agreeableness

5- Conscientiousness 
معتادان در مقايسه با تروه كواه در بعد روان رنجور خـويى

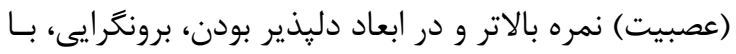
وجدان بودن نمرات يايين ترى كسـب كردنـد و در مولفـهـ شخصيتى انعطاف يذيرى در افـراد معتـاد و سـالم تفــاوت معنى دارى وجود ندارد. (جدول (1).

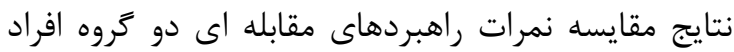

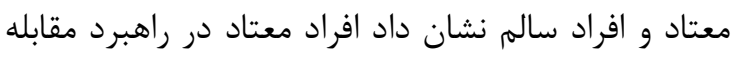

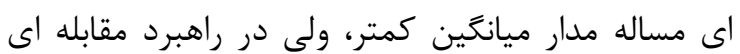
هيجان مدار ميانخين بيشترى را كسب كرده اند.

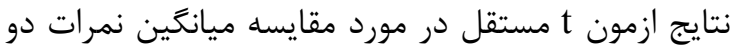

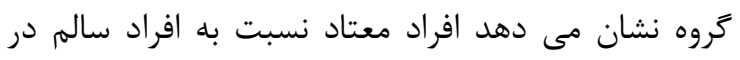

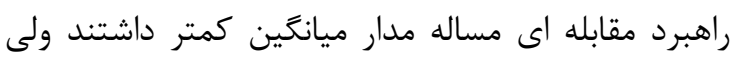

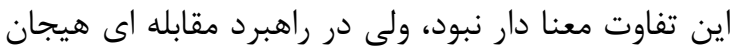

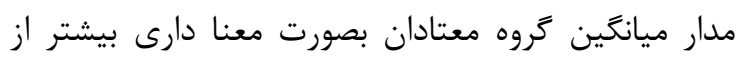

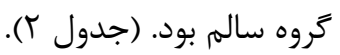

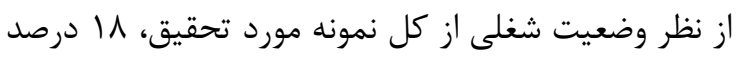

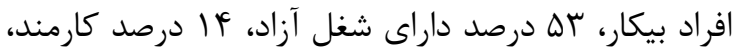
|f أ درصد دانشجو بودند.

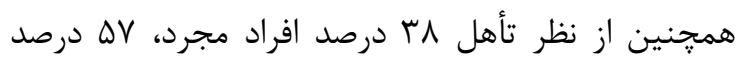

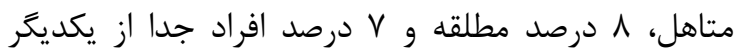

$$
\text { زندگى مى كردند. }
$$

طبق يافته هاى يروهش، ميانگين نمره هاى افر راد معتاد در بعد شخصيتى عصبيت داراى ميانگين بيشتر ولى در در ابعاد شخصيتى برونكرايى، دليذير بودن، انعطاف يذيرى و وإن

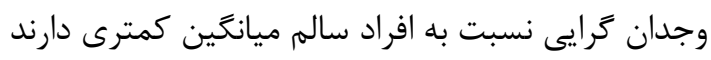
همجِنين نتايج ازمون t مستقل در مورد مقايسـه ميـانگين فرين

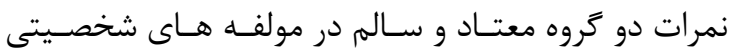

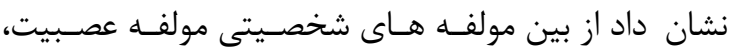

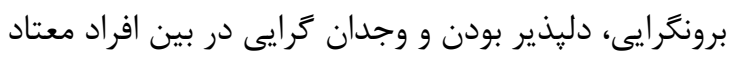

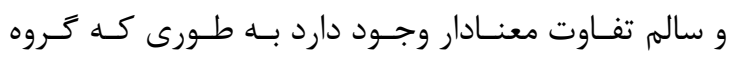

\begin{tabular}{|c|c|c|c|c|}
\hline سطح معنى دارى & انحراف معيار & ميانكين & كروه & زير مقياس \\
\hline \multirow[t]{2}{*}{$\mathrm{P}<\cdot / \cdot \cdot 1$} & $\Delta / \cdot \Delta$ & rN/FF & معتاد & عصبيت \\
\hline & $\varepsilon / V q$ & . & سالم & \\
\hline \multirow[t]{2}{*}{$\mathrm{P}<\cdot / \cdot \cdot 1$} & $\Delta / 9 \Delta$ & rY/GT & معتاد & برونكَرايى \\
\hline & $p / q p$ & $F \cdot / T F$ & سالم & \\
\hline \multirow[t]{2}{*}{$P<\cdot / \cdot q r$} & $\Delta / \cdot \Delta$ & $r \varphi / 94$ & معتاد & انعطاف يذيرى \\
\hline & $r / \cdot \Lambda$ & $r \mathrm{~N} / \mathrm{r}$ & سالم & \\
\hline \multirow[t]{2}{*}{$\mathrm{P}<\cdot / \cdot 1 \pi$} & $\Delta / \Gamma G$ & rV/AV & معتاد & دليذير بودن \\
\hline & $F / \cdot V$ & rq/Dr & سالم & \\
\hline \multirow[t]{2}{*}{$\mathrm{P}<\cdot / \cdot \cdot 1$} & $4 / 11$ & Tr/qT & معتاد & وجدان گرايى \\
\hline & $r / l r$ & $r q / 11$ & سالم & \\
\hline
\end{tabular}




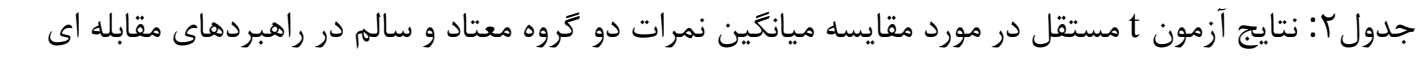

\begin{tabular}{|c|c|c|c|c|}
\hline $\mathrm{P}$ value & انحراف معيار & ميانگين & گروه & زير مقياس \\
\hline \multirow[t]{2}{*}{$\mathrm{P}=\cdot / 1 r \Delta$} & $\Delta / \cdot \Delta$ & Tr/kg & معتاد & مسأله مدار \\
\hline & $q / V q$ & $r \Delta / \mu^{\mu}$ & سالم & \\
\hline \multirow[t]{2}{*}{$P=\cdot / r 9 \Delta$} & ع & re/rq & معتاد & هيجان مدار \\
\hline & $9 / 9 r$ & $\mu F / \wedge \Delta$ & سالم & \\
\hline
\end{tabular}

سوى ديكر صرف نظر از سطح استرس براى تجربه هيجان

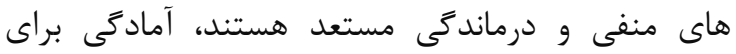
تجربه حوادث استرس زاى فراتر از حد معمول، تجربه

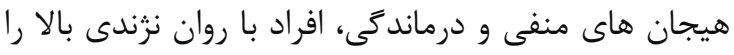

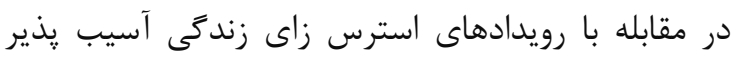

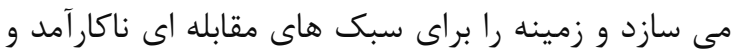

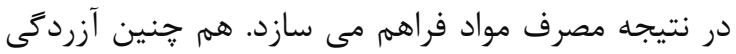

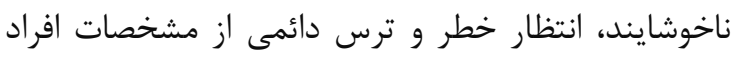
روان نزند مى باشد. اين مشخصات شخصيتى به نوعى يناه بردن به شيوه هاى نامتعارفى جون مصرف مواد مخدر رائ

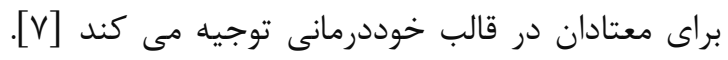

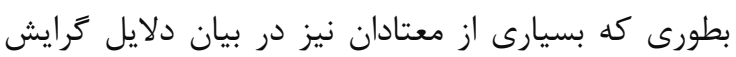
خود به مواد مخدر مشكلاتى خون آزردگى، انتظار خطر وترس را اظهار مى كنند. بنابراين در مطالعات يِيشيرانه

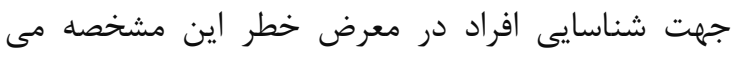

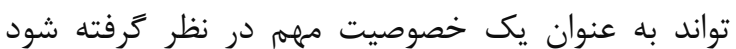
موضوعى كه در ارتباط با خانواده افراد مبتلا به اعتياد، عدم مسئوليت يذيرى اين افراد در قبال خود و ديخران است و همواره اين افراد محكوم به اين مشخصه هستند كه ائن درى صحيحى از تاثيرات منفى اعتيادشان بر ساير اعضا

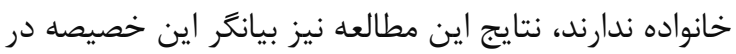

1-Kotov

2-Littlofield 
خود مى كيرند. آنها بجاى اينكه مسأله را حل كنند، تنها

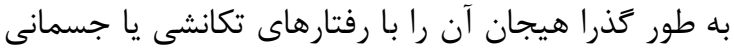

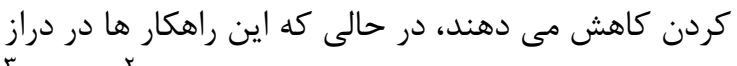

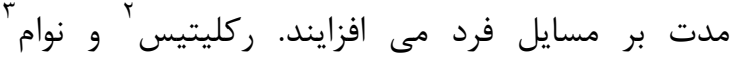
(1999) نشان دادند كه راهبرد حل مسأله و راهبرد هاى مركي

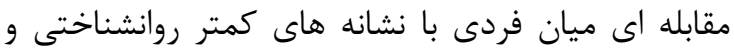

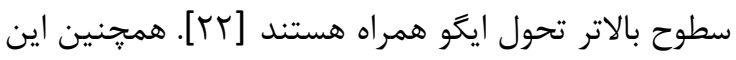

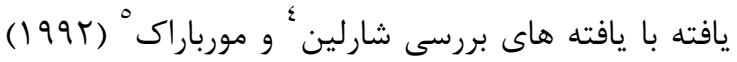

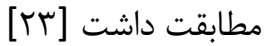

اين مطالعه داراى محدوديت هايى بود كه لازم است به ان ان اشاره شود.كروه مورد مطالعه ما همكَى مرد بودند و و نتايج بدست آمده قابل تعميم به بيماران زن نمى هودى باشد. همجنين تروه مورد مطالعه معتادان خود معرف مراجعه كننده به مراكز ترك بودند كه از لحاظ وضعيت روانشناختى با بيماران غير مراجعه كننده كه تمايلى به به بـ

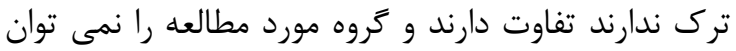
نماينده كل معتادين جامعه در نظر كرفت. بنابر دراين

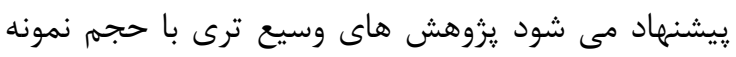
بزر كتر و از تمام كروه هاى معتادين انجام شود.

\section{نتيجه كيرى}

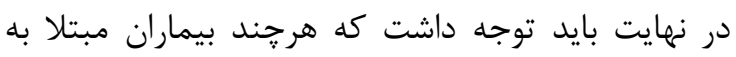
اعتياد داراى خصوصيات شخصيتى متفاوت هستند و اين تاين خصوصيات تاثير بارزى بر راهكارهاى مقابله با مشكلات انها كذاشته است ولى راهكار هاى مقابله اى قابل تغيير و باري

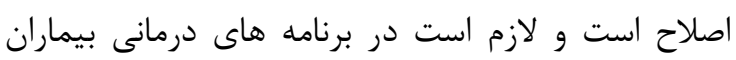
مراجعه كننده براى ترك به ان توجه ويزه شود.

\section{تشكر و قدردانى}

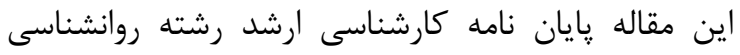

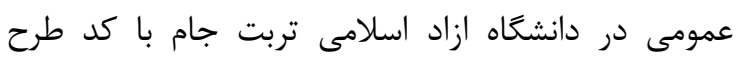

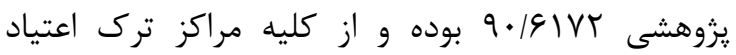
خصوصى كه با اينجانب همكارى داشتند قدردانى مى بوده شود.

2 -Recklitis

3 -Noam

4 -Sharelin

5 -Mor-Barak
بين افراد معتاد مى باشد. عدم وجود سطوح قابل قبولى از مسئوليت يذيرى در اين افراد، لزوم بكاركيرى روشهايى

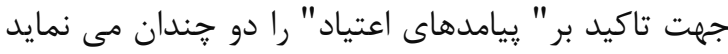

خصوصيت ديخرى كه در معتادان با افراد عادى تفاوت

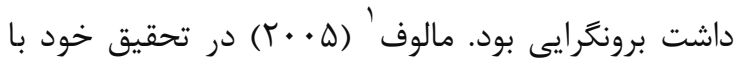

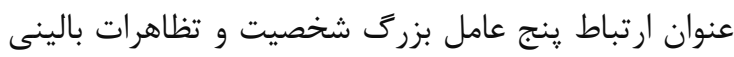

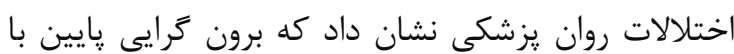
علائم اضطراب و اختلال خلق و اختلالات سايكو تيك ناني مرتبط است. يافته هاى بالينى در معتادان نيز نشان مئ إنى

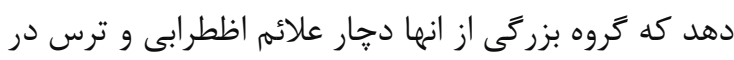
روابط بين فردى هستند و حساسيت نسبت به قضاوت

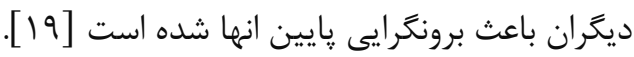

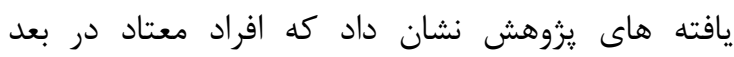
شخصيتى دليذير بودن و وجدان ترايى نمرات كمترى ندان

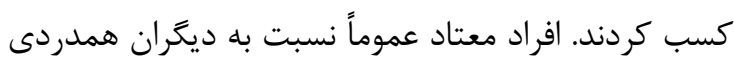

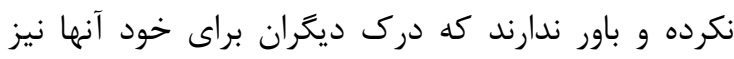

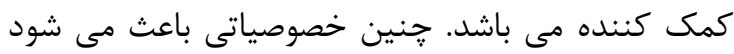

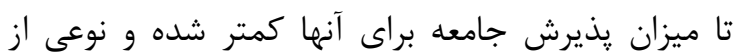
جرخه معيوب دور شدن بيشتر از افراد عادى جامعه و

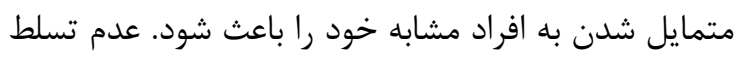

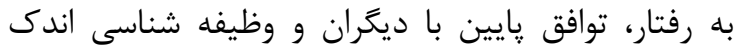

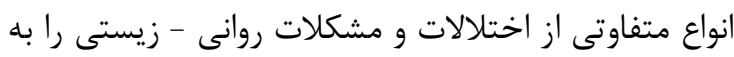

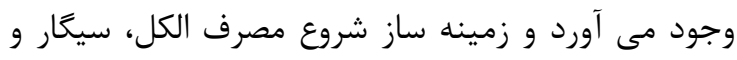

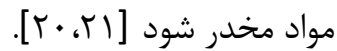
نتايج يزوهش نشان دادند بين راهبرد مقابله اى هيجان

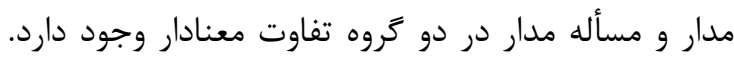

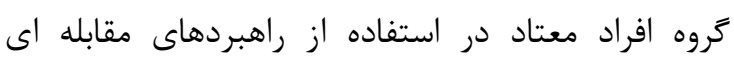
هيجان مدار نمره بالاترى را نسبت به گروه افراد غير معتاد

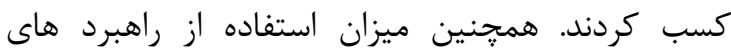

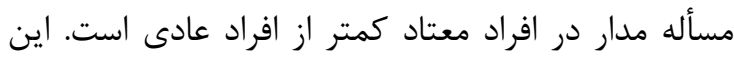

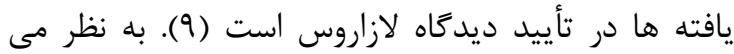

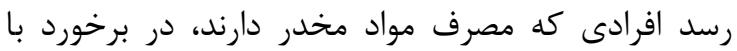

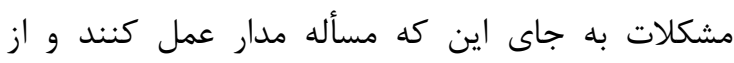

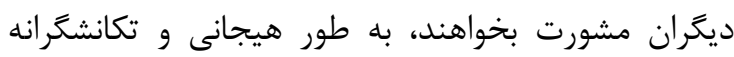
واكنش نشان مى دهند و در نتيجه فرصت حل مسأله را از

1 -Malouff 


\section{References}

1. Kreek MJ, LaForge KS and Butelman E, Pharmacotherapy of addictions, Nat. Rev. Drug Discov. 2002; 1(9):710-26.

2. Global illicit drug trends, WHO publication - UNDCP section 2003; pp 136 and overview p 101

3. Donnelan M.B.,Conger R.D., \& Bryant C.m.(2004), The big five and enduring marriges , journal of Research in Personality 2004 ,34; p 481-504.

4. Does change in drinking motives mediate the relation between personality change and "maturing out" of problem drinking? Journal of Abnormal psychology, 119 ; p 93-105.

5. Math S. B., Murthy P., Parthasarthy R., Kumar C. N. \& Madhusudhan S, (2011), Minds Imprisoned: Mental Health Care in Prisons, Publication, Bangalore: National Institute of Mental Health Neuro Sciences.

6. Costa PT, McCrae RR, The Revised NEO Personality Inventory (NEO-PI-R), The SAGE handbook of personality theory and assessment 2008;2:179-98.

7. Schultz DP, Schultz SE, Theories of Personality: Wadsworth, Cengage Learning; 2008.

8. Ball S, Personality traits, disorders and substance abuse, On the psychobiology of personality: essays in honor of Marvin Zuckerman 2004:203-22.

9. Lazarus RS, Folkman S, The concept of coping in stress, appraisal, and coping, New York, Springer, 1984; $\mathrm{p} 57$.

10. Brooner RK, Schmidt Jr CW, Herbst JH, Personality trait characteristics of opioid abusers with and without comorbid personality disorders 2002.

11. Grosi freshi M.T, Mehryar A.H, ghazi tabatabaei S.M , Testing of new NEO Personality Inventory (NEO) and analysis of its characteristics and factor structure among university students in Iran, J of human science of Al zahra university, 2001; 11(39) : 173-198.

12. Lazaurus R. S., f Folkman, S. (1985), Stress Appraisal and coping. New York, Springer, Pub, Company

13. Vahedi H,The survey of reliability and validity of copying strategies of high school students in Tehran, MA Thesis in Islamic Azad University of Tehran , 2001[Persian]
14. Carter JA, Herbst JH, Stoller KB, King VL, Kidorf MS, Costa Jr PT, "et al", Shortterm stability of NEO-PI-R personality trait scores in opioid-dependent outpatients, Psychology of Addictive Behaviors 2001;15(3):255.

15. Kotov R, Gamez W, Schmidt F, Watson D, Linking "big" personality traits to anxiety, depressive and substance use disorders: A meta-analysis. Psychological bulletin 2010; 136(5):768.

16. Littlofield A., sher K. J. \& wood P. K, Is 'maturing out' of problematic alcohol involvement related to personality change, Journal of Abnormal psychology, 2009:360376.

17. Hojjat SK,Vahidi G,The comparison of personality characteristic irrational beliefs between femailes with opium dependency and femailes with methamphetamine dependency, Journal of North Khorasan University of Medical Sciences Summer 2013;5(2):330[Persian]

18. Jones RM, Ross CN, Hartmann BR, An investigation of cognitive style and alcohol/work-related problems among naval personnel, Journal of drug education 1992;22(3):241-51.

19. Malouff J. M., Thoysteinsson E. B., Rooke S. E. \& Schutte N. S, Alcohol involvement and the five factor model of personality, A meta analysis,Journal of Drug Education, $2007 ; 37$ : 277-294.

20. Abu-Arab M. \& Hashem E. (1995), "Some Personality correlates in a group of drug addicts", Personality and Individual Differences 1995; 19(5):569-653.

21. Kessler RC, Chiu WT, Demler O, Merikangas KR, Walters EE, Prevalence, severity and comorbidity of 12-month DSMIV disorders in the National Comorbidity Survey Replication. Arch Gen Psychiatry 2005; 62(6): 617-27.

22. Recklitis C. J. \& Noam G. G. Clinical and developmental perspectives on adolescent coping, Child Psychiatry and Human Development 1999; 3: 87-101.

23. Sharelin S. A., \& Mor-Barak M, Runaway girls in distress: Motivation, background and personality, Adolescence 1992 ; 27: p 387-405. 


\title{
Comparison between personality traits and copying strategies in Substance dependent men and non dependent group
}

\author{
Kameli $D^{1}$, Hojjat $\mathrm{Sk}^{* 2}$, Jajarmi $M^{3}$, Abedi $A^{4}$,Kameli $T^{5}$ \\ ${ }^{1}$ M.A. of psychology, Islamic Azad University of Torbat-jam .Trbat-jam,Iran \\ ${ }^{2}$ Assistant professor of psychiatry, North Khorasan University of Medical Sciences,Addiction and Behavioral \\ sciences Research Center, Bojnurd, Iran \\ ${ }^{3}$ Assistant professor of Islamic Azad University.Bojnurd branch,Bojnurd,Iran \\ ${ }^{4}$ M.A of MBA.North khorasan education organization.Bojnurd,Iran \\ ${ }^{5}$ M.A student of psychology, Islamic Azad University of Bojnurd ,Iran
}

\begin{abstract}
*Corresponding Author: North Khorasan University of Medical Sciences,Addiction and Behavioral sciences Research Center, Bojnurd, Iran Email:

S.kavehhojjat1@gmail.com
\end{abstract}

\begin{abstract}
Background \& Objectives: In substance abuse treatment, attention to the personality traits and coping strategies need to a special consideration. This study aimed to compare between personality traits and coping strategies in substance dependent men and non-dependent group.

Materials \& Methods: The samples of study include all men in Bojnurd that referred to addiction rehabilitation centers. 100 substance dependent men were compared with 100 men without substance dependency. Evaluation tools included The NEO-PTR Questionnaire and Lazarus and Folkman coping strategies questionnaire.

Results: Patients with substance dependency showed significant higher neuroticism and lower extraversion, agreeableness, and conscientiousness in comparison with control group $(P<0.001)$ .There was no significant difference in flexibility. Also addicted patients showed higher use emotion-focused coping strategies and lower use problem-focused coping strategies in comparison with control group $(P=0.265)$

Conclusion: Although patients with substance dependency have different personality characteristics compared with non dependent group and these properties have a significant effect on their copying strategies, but copying strategies could change and improve by training and need to special consideration in treatment programs.

Keywords: coping strategies, personality, addiction, men
\end{abstract}

Submitted:26 Aug 2013

Revised:11 Jan 2014

Accepted: 26 Jan 2014 